IRA-International Journal of Management \&

Social Sciences

ISSN 2455-2267; Vol.17, Issue 01 (Q.1 2021)

Pg. no. 9-19.

IRA Academico Research

\title{
Situational Analysis on Nutritional Status of Adolescent Girls: A Study from Rural Karnataka, India
}

\author{
Dr.Rubavel $M^{1 \#}$, Dr. Jonas Richard $A^{2}$, Dr. Winnie Joyce $A^{3}$ \\ ${ }^{1}$ Assistant Professor, ${ }^{2}$ Professor \& Head, ${ }^{3}$ Assistant Professor \\ 1,2,3. Department of Social Work, Kristu Jayanti College ( Autonomous), Bengaluru, Karnataka, India. \\ \# corresponding author \\ Type of Work: Peer Reviewed. \\ DOl: https://dx.doi.org/10.21013/jmss.v17.n1.p2
}

\section{How to cite this paper:}

Rubavel M et al (2021). Situational Analysis on Nutritional Status of Adolescent Girls: A Study from Rural Karnataka, India. IRA-International Journal of Management \& Social Sciences (ISSN 2455-2267), 17(1), 919. DOI: https://dx.doi.org/10.21013/jmss.v17.n1.p2

(C) IRA Academico Research.

(c) B Br-Nc This work is licensed under a Creative Commons Attribution-NonCommercial 4.0 International License subject to a proper citation to the publication source of the work.

Disclaimer: The scholarly papers as reviewed and published by IRA Academico Research are the views and opinions of their respective authors and are not the views or opinions of IRA Academico Research. IRA Academico Research disclaims of any harm or loss caused due to the published content to any party.

IRA Academico Research is an institutional publisher member of Publishers International Linking Association Inc. (PILA-CrossRef), USA. IRA Academico Research is an institutional signatory to the Budapest Open Access Initiative. Hungary advocating the open-access of scientific and scholarly knowledge. IRA Academico Research is a registered content provider under Open Access Initiative Protocol for Metadata Harvesting (OAl-PMH).

The journal is indexed \& included in WorldCat Discovery Service (USA), CrossRef Metadata Search (USA), WorldCat (USA), OCLC (USA), Open J-Gate (India), EZB (Germany) Scilit (Switzerland), Airiti (China), Bielefeld Academic Search Engine (BASE) of Bielefeld University, Germany, PKP Index of Simon Fraser University, Canada. 


\section{ABSTRACT}

Adolescence is a critical period of life. This is a time of rapid development of the body, brain, and behaviours. They undergo puberty changes and also face difficulties that may affect health throughout life which is a setback for the growth of adolescent girls. It is important to study the nutritional status of adolescent girls. The study has been taken up on the Nutritional aspects of the Adolescent girls to focus on the Socio-Economic conditions of the families, Nutritional intake of the Adolescent Girls, and status of Body Mass Index (BMI) and Mid Upper Arm Circumference (MUAC) among the adolescents and to suggest recommendation to improve the Nutritional status of adolescent girls. This study would help to create a positive effect in reducing health problems and bring out strategies to improve the health condition of Adolescent Girls. It would help to create a positive effect on the problem of Maternal Mortality Ratio, Infant Mortality Rate, Neonatal Mortality Rate, and Crude Birth Rate. It may help to reduce the drop-out rate in school as well as in pursuing Higher Education. This study focuses on the situational analysis of the nutritional status of adolescents by measuring the BMI (Body Mass Index) in the rural villages of Karnataka, India, and suggests intervention strategies and proposes policies to enhance the health of the adolescent girls.

Key Words: Adolescent Girls, Nutritional Intake, Body Mass Index (BMI), Mid-upper arm circumference (MUAC)

\section{INTRODUCTION}

Adolescents aged 11-19 years constitute around one-sixth of the world's population. In India, the National Youth Policy defines adolescents as 13-19 years. Adolescence is increasingly recognized as a critical period in the life course. Adolescent health is crude because they undergo puberty changes. Adolescent girls undergo a lot of health problems and prone to vulnerability.

Few studies reveal that the prevalence such as $45 \%$ of girls found stunted and thinness was $14 \%$ for younger girls as per Body Mass Index - BMI (K Rose-Clarke). 60 percentages of girls among the age group of 15-19 are found to have anaemia. Adolescent health services are not accessible, unaffordable, and of poor quality.

Due to the prevalence of anaemia among adolescent girls, not only it affects the girl directly, but it is also related to the health of the new-born which in turn affects the health of the next generation. The health of the adolescent is very important which will have an adverse effect on Maternal Mortality Ratio, Infant Mortality Rate, Neonatal Mortality Rate, and Crude Birth Rate. An adolescent girl undergoes the process of learning life skills, completes schooling, and develops strong self-esteem and confidence. The adolescent`s health is crucial to take up higher studies and face challenges. The health of the Adolescents is very important and it throws light to study on the status of Health Status

\section{REVIEW OF LITERATURE}

World Health Organization (WHO), quotes that 43 percent of children in India are found as underweight children among the developing countries. It is found that India is not performing to the expected level in the health situation of children compared to neighbouring countries.

According to the Sample registration system bulletin (2013), India is experiencing a big diversity in the rate of infant mortality. The states like Madhya Pradesh (54) and Assam (54) have the highest no of infant deaths in the country. The states such as Uttar Pradesh (UP) (50), Rajasthan (47), Bihar (42), Haryana (41) Andhra Pradesh (39), have IMR above the national average (40) per thousand live births in 2013. Kerala (12) has the least number of IMR followed by Tamil Nadu (21) in 2013 (SRS).

Sivagurunathan (2015) In this study, it was observed that in both children of urban and rural schools the mean weight of adolescent girls was higher than the ICMR standards of mean weight in all the ages. The mean height was higher than the ICMR standard means the height of age group of $12-14$ and 17 years among rural girls.

ICMR Report - It was observed in the studies (in terms of weight and height) in the older adolescent age group (17-18 years) and early or middle adolescent age group (10-13 and 14-16 years), The parameters were 
higher than the ICMR standards. The impact in both adolescent weights for age and height for the age among adolescent girls was not reflected in the body mass index.

Bisai, et al., (2012) observed in the study that the rate of underweight is more with late adolescence than early adolescent's boys and Girls. In the study, it is found that the late adolescent age group members are conscious of health-related to weight. In the present study weight and height both to be increasing in a particular period, which means that adolescent girls are having a better nutritional status. This development in the nutritional status could be due to the Mid-day Meal scheme and better literacy rate. Research studies have shown that better-nourished girls have a better nutritional status which might lead to higher pre-monarchical growth and they have reached monarchical before than undernourished girls. Nutritional improvement is important for supporting the nutritional need of adolescents and sufficient food may bring better growth but also harm the risk of obesity. It is suggested to have physical exercise. The reason for the thinness is attributed to the poor socioeconomic conditions of rural Bangladesh. The poor nutritional status of adolescent girls has implications in terms of adverse effects on reproductive outcomes and their physical work capacity.

Patanwar, P., \& Sharma, K. K. N. (2013) It is found in many studies that adolescent girls of urban are more overweight than rural adolescent girls due to decreased sedentary lifestyle, physical activities, change in the eating patterns, and excessive fat content in the diet. Prevalence of obesity is common among adolescents. There is a higher possibility increased of Non-communicable diseases such as diabetes and hypertension.

Maity, B. (2015). Nutritional Status of School Children in Rural Scenario, Results show that boys are heavier than girls and girls are found taller than the boys in each age. The mean weight of the adolescent girls was much lower in comparison to ICMR standard specifications. Underweight is used as an indicator to determine acute undernutrition. Height and weight of all age groups are the most common measurements used to measure nutritional status among Adolescent Girls.

Alam, N., Roy, S. K., Ahmed, T., \& Ahmed, A. S. (2010). Nutritional status is measured with BMI-for-age of girls and height-for-age z-score. The prevalence of undernutrition was found in the study. It is found that 9 percentage of adolescent girls are severely thin and 16 percentage were moderately thin (in between the 5th and the 15th percentile value of BMI-for-age), and $0.3 \%$ obese. Undernutrition is the main concern among adolescent girls which is to be addressed and supported for better nutritional status. The effects may be delayed puberty. The knowledge of extra nutrients is another concern for the better health status of adolescent girls. Consumption of staple food (rice or wheat) is important. But other food such as fish, meat, and egg is a matter of concern. This study found that half of the adolescent girls did not eat meat and milk. It is around 40 percent of the adolescents did not eat eggs at all. The average days of food intake in a week were 3.4 for fish, 1.1 for eggs, 1.9 for milk, 0.6 for meat, 1.7 for dal and leafy vegetables each, and 2.3 for fruits. The accessibility of fruits is quite seasonal in rural Bangladesh. Fish and Meat are the main sources of animal protein and egg and milk (main sources of animal fat). These foods have to be given to adolescent girls for better health status.

Dietary knowledge, intake of iron is important for adolescent girls. The awareness of the Iron supplement is very important. Knowledge of food sources for energy and protein may be useful for adolescent girls are important. Adolescents expressed that rice is one of the energy-giving food and $31 \%$ of respondents mentioned rice and $12 \%$ of respondents mentioned wheat as energy food by the adolescent girls.

Awareness of high-protein foods such as dal (21\%), fish (43\%), and meat (32\%) and Knowledge of vitaminand mineral-rich food was common; $75 \%$ of respondents mentioned vegetables, and $51 \%$ respondents mentioned fruits as vitamin and mineral-rich foods. Two-thirds that is $64 \%$ percentage of the girls were aware of the importance to take extra nutrients for the adolescent to attain growth.

\section{METHOD AND MATERIALS}

This study focuses on the Nutritional status among adolescent girls in the villages of Karnataka, India. The descriptive design has been adopted in the study. This study has four objectives. The tool- Interview schedule has been prepared and collected from the adolescent girls in the villages of rural Karnataka, India. This empirical study was conducted using simple random sampling among the rural adolescent girls from five 
Villages of Rural Karnataka. In Each village, 10 samples were collected and a total of 50 samples were collected and analyzed. Adolescent girls with the age group of 13-16 have been selected as respondents and measured the Body Mass Index and Mid- Arm circumference (MUAC). Focus Group Discussion was conducted on the nutritional aspects of adolescent girls. This study also focused on intake of food in seven days duration would give an in-depth picture of the nutritional intake of adolescent girls in the rural area. The questions on socio-economic status would affect the nutritional intake of the adolescent girls. Body-Mass Index (BMI) is being calculated and compared between ICMR \& WHO Standards BMI Index are used for analysis and present study and see the difference. This study is going to present the extremes of weight (Obesity) \& Underweight and Thinness and Severe Thinness in the study for the interventions by the Karnataka Government and Ministry of Women and Child Development.

\section{OBJECTIVES}

- To understand the Socio-Economic situation of the families of Adolescent Girls

- To understand the nutritional Intake by the adolescent Girls

- To measure the Body Mass Index (BMI) \& Mid- Arm circumference (MAU) of Adolescents Girls.

- To suggest a recommendation for the project, program, and policies on the Nutritional supplement to the children.

\section{NUTRITIONAL PROBLEMS OF ADOLESCENT GIRLS}

The nutritional requirement should be higher among adolescents than in any other period of life. Inadequate diet intake at this age leads to stunted growth and delayed sexual maturation. The junk fruits could be avoided; there is the possibility to take unhealthy food due to the media intervention. These issues can be reduced by routine screening and nutritional education.

Due to lack of proper nutritional support to the adolescent girls and mental and physical health could be affected and prone to multiple diseases during their lifetime. It may help to reduce the drop-out rate of Adolescent girls in Higher Education. Adolescent girls undergo the process of learning in schools and develop strong self-esteem and confidence. The health of adolescents is crucial to take up higher studies and face challenges. India has the highest adolescent population in the world.

The adolescents' age group is a form of an important segment of the population. It is an important focus on the holistic health of adolescents. Physical health is an important component that contributes to the well-being of adolescents. There is no organized system to support and monitor the need for nutrition among adolescents.

WHO report in 2014 titled "Health for the world's adolescents" focuses on the health of adolescents. Because of this, the Government of India launched the comprehensive program for the adolescents 'Rashtriya Kishor Swasthya Karyakram' in January 2014. The scheme focuses on the adolescent's sexual and physical health, which aims to realize their full potential and to make responsible decisions to regard to adolescent health and well-being.

The physical health of adolescents is important, It previous study findings reveal that a million adolescents died due to preventable causes during 2012 as per the WHO report. It is found that in half of the mental health disorders in adulthood which starts at 14 years of age most cases are untreated and undetected among adolescents.

\section{RESULTS AND FINDINGS}

\section{Education of the Parents}

Socio-Economic Status of the adolescent girls is studied for a better understanding about the families which are basically on the parent's education and income of the parents. The socio-Economic Status of the adolescents was analyzed and presented. Parent Education plays a very important role in mentoring adolescent girls and would help educate the adolescent girls in the family. Parents could disseminate the information on the importance of nutrition, if they have been educated and if they have awareness. 
Parents Education (Table - 1)

\begin{tabular}{|l|l|l|l|}
\hline $\begin{array}{l}\text { SL } \\
\text { No }\end{array}$ & Parents Education & Frequency & Percentage \\
\hline 1 & Not Studied & 5 & 10 \\
\hline 2 & $1^{\text {st }}$ to $8^{\text {th }}$ STD & 19 & 38 \\
\hline 3 & $9^{\text {th }}$ to $12^{\text {th }}$ STD & 26 & 52 \\
\hline \multicolumn{2}{|c|}{ Total } & $\mathbf{5 0}$ & $\mathbf{1 0 0}$ \\
\hline
\end{tabular}

Parent's education plays a major role in terms of the health of the children. Parents would play an important role in providing healthy food and a balanced diet for the children. This would have a better impact on physical and Mental Health. However, it is important to check whether parent's education has the relationship between better health statuses of the adolescent. This study reveals that the higher the education and better the health statuses of the adolescent.

\section{The income of the parents}

Parents Occupation would play a better role in terms of contributing factors because occupation is linked with education and income. Occupation of parents plays important indicators for growth of the adolescent girls. Most of the parent occupations are agriculture work, which means they can get nutritional food products within the families such as vegetables, Greens, Pulses, milk, etc... However, the income source of the households seems to be less. It is the point of concern that needs to be addressed in the promotion of adolescent health. Parent's income would play a better role in terms of contributing factors because it is linked with supply of nutrition and plays important indicators for growth of the adolescent girls.

It is a base for meeting up the consumption needs of adolescent girls. Parents who are getting more income can meet the nutritional need of adolescent girls.

The income of the Parents (Table - 2)

\begin{tabular}{|l|l|l|l|}
\hline $\begin{array}{l}\text { SL } \\
\text { No }\end{array}$ & The income of the Parents & Frequency & Percentage \\
\hline 1 & Less than 5000 & 6 & 12.0 \\
\hline 2 & 5001 to 10000 & 30 & 60.0 \\
\hline 3 & 10001 to 15000 & 8 & 16.0 \\
\hline 4 & 15001 to 30000 & 6 & 12.0 \\
\hline 5 & 30001 and above & 6 & 12.0 \\
\hline & Total & $\mathbf{5 0}$ & $\mathbf{1 0 0}$ \\
\hline
\end{tabular}

Parents Income would help them to address the adolescent's nutritional needs of the adolescent girls. With better the income, Parents may be in the position to meet out the nutritional needs of the adolescent girls and they get sufficient income from the households. 
$12 \%$ of parents get less than Rs.5000/- as their income and also $60 \%$ of the parents are getting less than Rs.10, 000/- as their income. It is understood that most of the families fall under the low economic condition and it also reveals that parents may not be able to meet the nutritional needs of the adolescent girls.

\section{Comparative Analysis of this Study and ICMR Standards}

The data collected among the adolescent girls have been compared with ICMR Standards and this study results such as Age versus an average of Heights \& Weights have been presented below

\section{Comparative Analysis of this Study and ICMR Standards (Table - 3)}

\begin{tabular}{|r|r|r|r|r|}
\hline \multicolumn{3}{|c|}{ Study Results } & \multicolumn{2}{c|}{ ICMR Standards } \\
\hline \multicolumn{1}{|c|}{ Age } & Height & Weight & Height & Weight \\
\hline 13 & 151.33 & 37.70 & 150.0 & 44.0 \\
\hline 14 & 148.22 & 40.19 & 155.0 & 48.0 \\
\hline 15 & 150.19 & 42.84 & 161.0 & 51.5 \\
\hline 16 & 154.67 & 49.75 & 162.0 & 53.0 \\
\hline
\end{tabular}

The analysis shows in this study that Height and Weight are far below ICMR standards ((Nutrient Requirements \& Recommended Dietary Allowances for Indians, I.C.M.R. 1990) and the study reveals that there is more attention to be given to adolescents health. The Nutritional supplements to be given in terms of enhancing the health status of adolescent girls.

\section{Knowledge on the Healthy Food}

Knowledge of Iron, Vitamins \& Minerals and Calcium would help to improve the health status of adolescent girls. Adolescent girls should be aware of nutritional intake that would help them to get consciously aware of the importance of health.

Knowledge of healthy Food (Table - 4)

\begin{tabular}{|l|l|l|l|}
\hline SL & Variables & \multicolumn{2}{|l|}{ Response \& Percentage } \\
\cline { 3 - 4 } No & & Yes & No \\
\hline 1 & Knowledge of Iron Tablets & $58 \%$ & $44 \%$ \\
\hline 2 & Knowledge on Vitamins \& Minerals & $46 \%$ & $54 \%$ \\
\hline 3 & Knowledge on Calcium & $28 \%$ & $72 \%$ \\
\hline
\end{tabular}

Knowledge of the nutritional intake among adolescents has been studied and presented here. It is found that around $44 \%$ of adolescent girls are not aware of the Iron tablets, 54\% of them not aware of Vitamins \& Minerals, and $72 \%$ of adolescents not aware of calcium. It is important to understand the awareness levels of adolescent girls and awareness has to be provided on the healthy food items. These would help adolescent girls to take nutritional food to enhance the health status. 


\section{Intake of Food among the adolescent girls}

Intake of food is very important among the adolescent girls, the Intake such as Vegetable, Green, Pulses and Iron tablets. The Intake of food has been analyzed and presented below

Intake of Food among the adolescent girls (Table -5)

\begin{tabular}{|l|l|l|l|}
\hline \multirow{2}{*}{ No } & Variables & \multicolumn{2}{l|}{ Response \& Percentage } \\
\cline { 3 - 4 } & & Yes & No \\
\hline 1 & Three Meal a Day & $96 \%$ & $4 \%$ \\
\hline 2 & Intake of Vegetables Daily & $100 \%$ & $0 \%$ \\
\hline 3 & Intake Greens & $100 \%$ & $0 \%$ \\
\hline 4 & Intake of Pulses & $100 \%$ & $0 \%$ \\
\hline 5 & Intake of Iron Tablets ( Folic Acid) & $42 \%$ & $58 \%$ \\
\hline
\end{tabular}

As a primary analysis, It is found that around $4 \%$ percentage of adolescent girls are not taking three meals in a day which could be addressed and to be ensured to take three meals a day. Another concern is that adolescent girls are getting into puberty changes. It is suggested to take Iron tablets but the study results show that more than half of the adolescent girls are not taking the tablets. This problem could be addressed to ensure taking the Iron tablets among adolescent girls.

Intakes of Vegetables are one of the important aspects that contribute to better nutritional status. It would be helpful for the growth of children. The regular intake of the vegetables would help the adolescent girls as Vegetable contains minerals and Vitamins.

Daily Greens and Fruits would helpful for the growth of the child. Which would help them to have better health status. All can take Greens and Vegetables, Protein intake among the adolescent which would help the girls' development. It would help in the Growth and better health status in terms of development. Protein helps physical health development. This would contribute weight and heights of the adolescent girls in terms of BMI. Protein intake of the adolescent would help the girls to develop. It would help the Growth and better health status in terms of development.

\section{Intake of Nutritional Food - Within Seven Days in a Week}

There are certain foods people may not afford to take regularly and may take regularly. It has been decided to analyze that whether adolescent girls can take food items such as Fish, Meat, Egg, Milk, Dal, Leafy vegetables, and Fruits within seven days of time-frequency. The analysis has been taken up and has been analyzed and presented below 
Intake of Nutritional Food - Within Seven Days (Table - 6)

\begin{tabular}{|l|l|l|l|}
\hline SL & Variables & \multicolumn{2}{|l|}{ Response \& Percentage } \\
\cline { 3 - 4 } & & Yes & No \\
\hline 1 & Fish & 40 & 60 \\
\hline 2 & Meat & 48 & 52 \\
\hline 3 & Egg & 64 & 36 \\
\hline 4 & Milk & 82 & 18 \\
\hline 5 & Dal & 98 & 02 \\
\hline 6 & Intake Leafy Vegetable & 96 & 04 \\
\hline
\end{tabular}

It is found in the study that most adolescent girls are not taking food that contains a high level of protein with calories. It is also found that parents do not afford to buy Non- Vegetarian food in the households. The income of the parents is also linked with the consumption of Nutritional food of adolescent girls. It is important that we need to create awareness among the parents and adolescent girls for the consumption of Nutritional food or Nutritional supplements. It is found that 60 Percentage of respondents are not taking Fish, 52 Percentage of respondents not taking Meat and 32 percent of the adolescent are not taking eggs seven days a week.

Teachers have to create awareness among adolescents in the school so that intake nutritional intake regularly. Locally available low-cost nutritional food could be taken by the adolescent Girls. Adolescent girl's health should be taken care of because it may adversely affect MMR \& IMR across the states in India. The health of the adolescent girl is the health of the Women. The health of the Women in the health of the country.

\section{ANALYSIS OF MID ARM CIRCUMFERENCE}

Mid-Arm Circumference is one of the measurements to identify thinness among children and adolescents. The mid-arm circumference cut-off has been given in the previous studies (Sethi, V., et al, 2019). This study found that the mean of the MUAC value is greater than the cut-off value of the previous study. As per this assessment that generally adolescents are not falling under thinness and however when we take individual cases there few adolescent girls are fall under thinness and Severe thinness.

ANALYSIS OF MID ARM CIRCUMFERENCE (Table - 7)

\begin{tabular}{|l|l|r|}
\hline Age & $\begin{array}{l}\text { MUAC cut-off } \\
\text { (cm) }\end{array}$ & $\begin{array}{l}\text { Study Results } \\
\text { (Average) }\end{array}$ \\
\hline 13 Years & $\leq 20 \cdot 1$ & 22.90 \\
\hline 14 Years & $\leq 20 \cdot 6$ & 24.22 \\
\hline 15 Years & $\leq 20 \cdot 8$ & 24.43 \\
\hline 16 Years & $\leq 21 \cdot 6$ & \\
\hline
\end{tabular}


Adolescent girls fall under Thinness and Severe Thinness. The government needs to address and support has to be extended to adolescents by providing guidance and supporting for the nutritional food and supplements. Special attention needs to be given to the students.

\section{ANALYSIS OF BMI STATUS}

The study has been explored two extremes of Obesity \& Overweight and Thinness \& Severe Thinness to understand the trends and devise a strategy for the intervention for Adolescent girls in rural areas. It is found that $18 \%$ of Adolescent girls are at risk due to Mal- Nutrition. This needs to be addressed with the various strategic interventions and development projects Programmes for exclusively adolescent girls.

Policy Draft would be prepared to address the Health of the Adolescent Girls and would be submitted to the Government of Karnataka and the Ministry of Women and Child Welfare. Malnutrition among adolescent Girls would affect diseases such as Iron deficiency anemia, Low weight-for-height is known as wasting, prone to Infectious diseases such as diarrhea, etc. All these ultimately affect in studies in students and they may be a hindrance in perusing higher education.

It is also found that only $8 \%$ of adolescent Girls fall under Obesity and Overweight. This adolescent could be facilitated for physical exercise and diet control to address the problem. If we do not address the problems, they may get into diseases such as high blood pressure, heart disease, and strokes, sleep apnea, osteoarthritis. Fatty liver disease, Kidney disease, etc

\section{Findings}

1. Higher education of Parents and better the health statuses of the adolescent.

2. Higher-income of the Parents and better the health statuses of the adolescent.

3. The analysis shows in this study that Height and Weight are far below ICMR standards except for the age of 13 Years.

4. It is found that around $44 \%$ of adolescent girls are not aware of the Iron tablets, $54 \%$ of them not aware of Vitamins \& Minerals, and $72 \%$ of adolescents not aware of calcium.

5. Only $4 \%$ percentages of adolescent girls are not taking a three-meal in a day which could be addressed and it is ensured to take three meals a day. However, in the qualitative discussion with adolescent girls, It is found more than $4 \%$ of respondents are skipping breakfast due to their economic condition of families and lack of time.

6. Parents who are getting income more than Rs. 15001 and their children are not falling under thinness and severe thinness.

7. It is about $60 \%$ of the Adolescent Girls not taking Fish, 52\% of the respondents not taking Meat, 36 $\%$ of them not taking egg in Seven days.

8. More than half of the adolescent girls are not taking the tablets.

9. It is around $18 \%$ of Adolescent girls fall under thinness and Sever Thinness. They are at risk due to the Mal- Nutrition

10. It is around $8 \%$ of adolescent Girls fall under Obesity and Overweight and this issue also to be addressed.

\section{Recommendations to improve the nutritional aspects of Adolescents Health}

\section{Recommendations to School}

1. Awareness to be given on Intake of Balanced Diet among the adolescent girls

2. Awareness on not to get into unhealthy LifeStyle oriented food hobbits due to the influence of Media.

3. Training on the preparation of Nutritional Food for the parents to enhance the nutrition

4. Creating Awareness on the problem of anaemia and the importance of among Adolescent Girls in the School.

5. Training on micronutrients to combat micronutrient deficiencies of Adolescent Girls.

6. Delivery of iron supplement to Adolescent Girls in schools. 
7. Training on the importance of nutrition focuses on growth and skeletal development.

8. Dietary education could be given in schools and communities.

9. Introduction of Behaviour-Change Communication (BCC) among school-going and students who are not going to the school and also communities.

\section{Recommendations to Government}

1. Operation research may be taken up to address the nutritional problems to provide supplementary nutrition to address the Malnutrition

2. Communication materials could be developed to sensitize policy-makers, service providers, and teachers to work together and to increase participation in community-based adolescent girl's forums.

3. The behavior-change communication BCC model is to be established in all the Zones of our Country.

4. The government needs to address the micronutrient deficiency, undernutrition, low dietary knowledge, and low coverage of iron supplements among adolescent girls.

5. Project or Model could be developed addressing the nutritional health of Adolescent Girls and Model can be replicated across the states.

6. The parent can be given training on ensuring a Balanced Diet and providing Nutritional supplements for ensuring the better health of adolescent girls.

\section{Recommendations to Parents}

1. Providing Nutritional Supplements and Ensuring the Balanced Diet to adolescent Girls

2. Ensuring micronutrients for adolescent Girls

3. Ensuring Iron Tablets for the adolescent girls from Primary Health Centres

\section{Recommendations to the Adolescents Girls}

1. Understanding the importance of nutrition and Intake of Nutritional Food with micronutrients.

2. Following the Balanced Diet without skipping breakfast.

3. Sharing the information on the importance of nutrition to other students in school and as well as communities.

\section{Discussion}

It is found that there is variation between the Indian Standards of (ICMR) and in the present study. Few Students skip their breakfast due to various reasons such as poor economic background and there is no time to take breakfast in the morning. Here, the study results in two extremes Overweight and underweight. These disparities need to address by training them on Balance Diet, Suggesting them to take nutritional supplements and basic exercise would help them to have a better health condition.

It is the need of the hour to address adolescent health because women's health is very important. Better women's health would lead to a healthier society. Most of the diseases have emerged at the age of the adolescent period of life. We need to ensure better health during the age of Adolescent.

This study also reflects that adolescent girls are not taking protein-rich food such as Fish, Meat, and egg within the seven days. Adolescent girls are not aware of Iron, Vitamins, Minerals, and calcium-oriented food for better health. Knowledge about this food was limited among adolescent girls. The awareness to be created among the adolescent girls on Iron, vitamins, Minerals, and calcium-rich food and the importance intake of food for better health.

In Quantitative data, it is found that $4 \%$ of the respondents skipping breakfast but it is found in the qualitative discussion, it is found that more than $4 \%$ of the adolescents are skipping breakfast due to various reasons. This is one of the grey areas which need to be addressed among adolescent students. It is found that few students are hesitant to express that they are skipping breakfast.

There is a need to develop a project, scheme, programs for addressing Health Issues of adolescent girls based on the findings of the study such as addressing the importance of breakfast and Intake of Iron, Vitamin, 
Minerals and calcium and intake of Fish, Meat \& Egg in a weak would help them rather than general intervention.

\section{Conclusion}

This research study helped to have a better understanding of the Nutritional status of adolescent girls which helps us to design a project, strategies, and model to intervene in the health of the adolescent girls. It helps to promote healthy generations and reduce the Maternal Mortality Ratio, Infant Mortality Rate, Neonatal Mortality Rate, and Crude Birth Rate. Through these interventions, girls could be able to pursue higher education and face the challenges in the different life situation and also could have Improved Health Condition of Adolescent Girls. Improved Health Condition helps to reduce the drop-out rate and enhance Higher Education among adolescent girls. The Muti-stakeholders approach could be adopted and involved policymakers, politicians, parents, teachers, community members, peer groups, NGOs, and government. Village Gram Panchayats could also address the problems. Policy draft could be prepared and submitted to the government of Karnataka and the Ministry of Women and Child welfare. The creation of awareness on the importance of nutrition among the parents and developing ways and mean of enhancing the income of the households also would help to address the nutritional health of adolescent girls.

\section{Reference}

[1]. Alam, N., Roy, S. K., Ahmed, T., \& Ahmed, A. S. (2010). Nutritional status, dietary intake, and relevant knowledge of adolescent girls in rural Bangladesh. Journal of health, population, and nutrition, 28(1), 86. DOI: https://doi.org/10.3329/jhpn.v28i1.4527

[2]. Bisai, S., Khongsdier, R., Bose, K., \& Mahalanabis, D. (2012). The double burden of malnutrition among urban Bengalee adolescent boys in Midnapore, West Bengal, India. Nature Precedings, 1-1. DOI: https://doi.org/10.1038/npre.2012.7106.1

[3]. Maity, B. (2015). Nutritional Status of School Children in Rural Scenario. International Journal of Sociology, Social Anthropology and Social Policy, 1(2), 13-26. DOI: https://doi.org/10.5958/2454-4833.2015.00013.3

[4]. Patanwar, P., \& Sharma, K. K. N. (2013). Nutritional status of Kurmi adolescent girls of Raipur city Chhattisgarh, India. Int J Sci Res Pub, 3, 1-6.

[5]. Satia, J. (2018). Challenges for adolescent health programs: What is needed?.Indian journal of community medicine: official publication of Indian Association of Preventive \& Social Medicine, 43(Suppl 1), S1. DOI: https://doi.org/10.4103/ijcm.IJCM_331_18

[6]. Sethi, V., Gupta, N., Pedgaonkar, S., Saraswat, A., Singh, K. D., Rahman, H. U., . \& Unisa, S. (2019). Mid-upper arm circumference cut-offs for screening thinness and severe thinness in Indian adolescent girls aged 10-19 years in field settings. Public health nutrition, 22(12), 2189-2199. DOI: https://doi.org/10.1017/S1368980019000594

[7]. Sivagurunathan, C., Umadevi, R., Rama, R., \& Gopalakrishnan, S. (2015). Adolescent health: present status and its related programs in India. Are we in the right direction?. Journal of clinical and diagnostic research: JCDR, 9(3), LE01. DOI: https://doi.org/10.7860/JCDR/2015/11199.5649

[8]. Sachan, B., Idris, M. Z., Jain, S., Kumari, R., \& Singh, A. (2012). Nutritional status of school-going adolescent girls in Lucknow District. Journal of Medical Nutrition and Nutraceuticals, 1(2), 101. DOI: https://doi.org/10.4103/2278-019X.101298

[9]. Sample registration system bulletin (2013) Census of India Website: Office of the Registrar General \& Census Commissioner, India (censusindia.gov.in) Accessed on 24.02.2021

[10]. World Health Organization. (2010). World health statistics 2010. World Health Organization. 